\title{
Prediction of the next day maximum ozone concentration using multiple linear and principal component regressions
}

\author{
S. I. V. Sousa, F. G. Martins, M. C. Pereira \\ \& M. C. M. Alvim-Ferraz \\ Departamento de Engenharia Química, LEPAE, \\ Faculdade de Engenharia, Universidade do Porto, Portugal
}

\begin{abstract}
Prediction of ground-level ozone concentrations is very important due to the negative impacts of this pollutant on human health and environment. Multiple linear regression (MLR) and principal component (PCR) regression were used as statistical models for the forecasting of ozone concentrations. The aim of this study was to predict the next day maximum ozone concentration. The studies were performed considering separately the year 2002 and the respective four trimesters. A subset of the last 10 and 30 days was used, respectively, for each trimester and for the year to validate the models. The predictor variables were inferred by the analysis of the linear correlation with ozone. For that, maxima hourly values for ozone, ratio of nitrogen dioxide and nitrogen monoxide, temperature, wind velocity and the minima hourly values for carbon monoxide and relative humidity were used. The main results achieved were: i) the performance indexes obtained for validation datasets were usually higher with PCR; ii) the number of principal components considered to develop the PCR was dependent of the dataset considered; iii) the PCR is more robust than MLR because collinearity effects are accounted with the first approach; iv) PCR model is shown to be a useful tool to provide protection for the public, through the use of early warnings for the population.

Keywords: ground-level ozone forecasting, multiple linear regression, principal component analysis, principal component regression.
\end{abstract}




\section{Introduction}

Tropospheric ozone is a secondary photochemical air pollutant which has negative impacts on human health, climate, vegetation, materials and atmospheric composition. The most significant effects on human health are related with a decrease in pulmonary function, attacks of asthma and chronic bronchitis, and globe ocular damages White et al. [1]. In terms of climate it is considered an important greenhouse gas so the increasing of ozone concentrations is related with an increasing of the surface temperature. In vegetation it has harmful effects especially during the growing season WHO [2].

Surface ozone formation results from a chain mechanism involving photochemical reactions of $\mathrm{NO}_{x}, \mathrm{VOCs}, \mathrm{CO}$ and $\mathrm{CH}_{4}$ Seinfeld and Pandis [3]. Ozone concentrations have been increasing significantly since pre-industrial times due to the increased photochemical production associated with the increase of anthropogenic emissions Alvim-Ferraz et al. [4]. Thus, it is very important to develop tools able to predict ozone concentrations and to provide early warnings to the population. Generally, ozone concentrations are very difficult to model, because of the different interactions between pollutants and between pollutants and meteorological variables. Principal component analysis is one of the approaches, which has been receiving attention as an accepted method in environmental pattern recognition. This multivariate statistical technique transforms the original data set into an equal set of linear combinations of the original variables. The new variables named principal components (PC) are uncorrelated and account for the majority of the original variance Gonçalves et al. [5]; Abdul-Wahab et al. [6]; Lengyel et al. [7].

The aim of this work was to analyse the relative importance of the concentration of precursors and meteorological variables in ozone formation, using principal component analysis, and to predict ozone concentrations. The performance of these models was compared through the evaluation of the mean bias error, the mean absolute error, the root mean squared error and the index of agreement.

\section{Methodology}

\subsection{Data}

The air quality data used was collected from an urban site with traffic influences, situated in Oporto, integrated in the measuring conducted by the Air Quality Monitoring Network of Oporto Metropolitan Area (Oporto-MA), managed by the Regional Commission of Coordination and Development of Northern Portugal (Comissão de Coordenação e Desenvolvimento Regional do Norte), under the responsibility of the Ministry of Environment. The meteorological parameters used were measured in the left edge of Douro River, at an approximate altitude of $90 \mathrm{~m}$, by the Geophysical Institute of Oporto University (Instituto Geofísico da Faculdade de Ciências da Universidade do Porto). 
Oporto is situated in the North of Portugal and has a latitude and longitude of approximately $41^{\circ} 10^{\prime} \mathrm{N}$ and $8^{\circ} 40^{\prime} \mathrm{W}$, respectively. The annual average temperature is around $15^{\circ} \mathrm{C}$ and the difference between warmer and colder monthly averages is less than $10^{\circ} \mathrm{C}$. Annual air humidity is between $75 \%$ and $80 \%$, and the total annual mean precipitation varies between $1000 \mathrm{~mm}$ and 1200 $\mathrm{mm}$, with about $40 \%$ in the winter season. Prevailing winds are from $\mathrm{W}$ and NW in summer and from E and SE in winter Pereira et al. [8].

This study considered as variables the values of ozone $\left(\mathrm{O}_{3}\right)$, ratio of nitrogen dioxide and nitrogen monoxide $\left(\mathrm{NO}_{2} / \mathrm{NO}\right)$, carbon monoxide $(\mathrm{CO})$, particulate matter with an equivalent aerodynamic diameter smaller than $10 \mu \mathrm{m}\left(\mathrm{PM}_{10}\right)$, sulphur dioxide $\left(\mathrm{SO}_{2}\right)$, temperature $(\mathrm{T})$, wind velocity $(\mathrm{WV})$ and relative humidity (RH).

Ozone concentrations were monitored by UV-absorption photometry; $\mathrm{PM}_{10}$ concentrations were obtained through the beta radiation attenuation method, $\mathrm{SO}_{2}$ concentrations were obtained through UV Fluorescence method; CO concentrations were measured through IV spectroscopy without dispersion; NO and $\mathrm{NO}_{2}$ were obtained through chemiluminescence method. The monitoring is continuous and hourly averages are recorded expressing the concentration in $\mu \mathrm{g} . \mathrm{m}^{-3}$. All the equipments were submitted to a rigid maintenance program being periodically calibrated.

The meteorological parameters were continuously measured, the hourly averages being considered in this study.

This study considered as predictor variables the maxima hourly values of ozone $\left(\mathrm{O}_{3}\right)$, ratio of nitrogen dioxide and nitrogen monoxide $\left(\mathrm{NO}_{2} / \mathrm{NO}\right)$, temperature (T), wind velocity (WV) and the minima hourly values of carbon monoxide (CO) and relative humidity $(\mathrm{RH})$. The concentrations of particulate matter with an equivalent aerodynamic diameter smaller than $10 \mu \mathrm{m}\left(\mathrm{PM}_{10}\right)$ and of sulfur dioxide $\left(\mathrm{SO}_{2}\right)$ were considered in the correlation study but no correlation was found between this variables and $\mathrm{O}_{3}$.

\subsection{Models}

Multiple linear regression (MLR) and principal component regression (PCR) were used to predict the next day maximum ozone concentration, with other air pollutant concentrations and meteorological parameters as predictors.

MLR is an extension of a simple linear regression model incorporating several explanatory variables in a prediction equation, for a response variable. The general equation is as follows:

$$
\hat{Y}=P_{0}+P_{1} X_{1}+\ldots+P_{n} X_{n}
$$

where $P_{\mathrm{i}}(\mathrm{i}=1, \ldots, \mathrm{n})$ are the parameters generally estimated by least squares and $X_{\mathrm{i}}(\mathrm{i}=1, \ldots, \mathrm{n})$ are the explanatory variables (predictors).

MLR models have been extensively used for $\mathrm{O}_{3}$ prediction, although these predictions are simply based on linear and additive associations of the 
explanatory variables and are highly sensitive to colinearities of the data Heo and Kim [9]; Thompson et al. [10].

The PCR combines the principal component analysis (PCA) and the MLR to determine the relevant independent variables for the prediction of $\mathrm{O}_{3}$ concentrations. PCA is a multivariate statistical method widely used in air pollution analysis. The objective of PCA is to reduce the number of predictive variables and transform them into new variables or principal components (PC) that are independent linear combinations of the original data, retaining the maximum possible variance of the original set. The eigenvalues of the standardized matrix are calculated through eqn (2):

$$
|C-\lambda I|=0
$$

where $\mathrm{C}$ is the correlation matrix of the standardized data, $\lambda$ are the eigenvalues and $\mathrm{I}$ is the identity matrix. The weights of the variables in the PC are then obtained by eqn (3):

$$
|C-\lambda I| W=0
$$

where $\mathrm{W}$ is the matrix containing the weights. To analyse the influence of the variables in PC, values of rotated factor loadings were calculated through varimax rotation. These loadings represent the contribution of corresponding variables to each principal component.

The $\mathrm{PC}$ used for the prediction of $\mathrm{O}_{3}$ concentrations were obtained through the multiplication of the standardized data matrix by the weights $(\mathrm{W})$ previously calculated Çamdevýren et al. [11]; Slini et al. [12].

The applicability of the PCA to the datasets used in the study was verified through the application of Bartlett's sphericity test expressed by the following equation Peres-Neto et al. [13]:

$$
\chi^{2}=-\left[\mathrm{n}-\frac{1}{6}(2 \mathrm{p}+11)\right] \ln |\mathrm{R}|,
$$

where $|\mathrm{R}|$ is the determinant of the correlation matrix, $\mathrm{n}$ is the sample size and $\mathrm{p}$ the number of variables. The distribution is $\chi^{2}$ with $\mathrm{p}(\mathrm{p}-1) / 2$ degrees of freedom. The null hypothesis here considered was that all variables are uncorrelated, and if accepted the PCA can be applied.

\subsection{Performance indexes}

The statistical parameters taken into account to evaluate the behaviour of the MLR and the PCR in the two steps of the models implementation (development 
and validation) were mean bias error (MBE), mean absolute error (MAE), root mean squared error (RMSE) and index of agreement (IA) given by eqns (5), (6), (7) and (8), respectively:

$$
\begin{aligned}
& \mathrm{MBE}=\frac{1}{\mathrm{n}} \sum_{\mathrm{i}=1}^{\mathrm{n}}\left(\hat{\mathrm{Y}}_{\mathrm{i}}-\mathrm{Y}_{\mathrm{i}}\right) \\
& \mathrm{MAE}=\frac{1}{\mathrm{n}} \sum_{\mathrm{i}=1}^{\mathrm{n}}\left|\hat{\mathrm{Y}}_{\mathrm{i}}-\mathrm{Y}_{\mathrm{i}}\right| \\
& \text { RMSE }=\sqrt{\frac{1}{n} \sum_{i=1}^{n}\left(Y_{i}-\hat{Y}_{i}\right)^{2}} \\
& I A=1-\frac{\left[\sum_{i=1}^{N}\left|\hat{Y}_{i}-Y_{i}\right|^{2}\right]}{\left[\sum_{i=1}^{N}\left(\left|\hat{Y}_{i}-\bar{Y}_{i}\right|+\left|Y_{i}-\bar{Y}_{i}\right|\right)^{2}\right]} .
\end{aligned}
$$

The MBE indicates if the observed concentrations are over or under estimated. The MAE and the RMSE measure residual errors which give a global idea of the difference between the observed and modelled values. The values of IA indicate the degree of which the predictions are error free, because it compares the difference between the mean, the predicted and the observed concentrations Chaloulakou et al. [14]; Gardner and Dorling [15].

\section{Results and discussion}

An analysis of the correlation coefficients between pollutants and meteorological parameters available was performed to evaluate the influence of each variable on the $\mathrm{O}_{3}$ concentrations. These coefficients provide a measure of the linear relation between the two considered variables.

The results showed positive correlations between ozone and the ratio nitrogen dioxide and nitrogen monoxide $\left(\mathrm{NO}_{2} / \mathrm{NO}\right)$, the temperature $(\mathrm{T})$ and the wind velocity (WV); and negative correlations with relative humidity $(\mathrm{RH})$ and carbon monoxide (CO). The concentrations of particulate matter with an equivalent aerodynamic diameter smaller than $10 \mu \mathrm{m}\left(\mathrm{PM}_{10}\right)$ and of sulphur dioxide $\left(\mathrm{SO}_{2}\right)$ were considered in the correlation study but no correlation was found between this variables and $\mathrm{O}_{3}$. Thus, the variables used to predict the next day maxima $\mathrm{O}_{3}$ concentrations were the maxima hourly values for $\mathrm{O}_{3}$, ratio of $\mathrm{NO}_{2} / \mathrm{NO}, \mathrm{T}, \mathrm{WV}$ and the minima hourly values for $\mathrm{CO}$ and $\mathrm{RH}$.

Five datasets were considered corresponding to the complete year (1 dataset) and the trimesters (4 datasets) of 2002. 
The results of Bartlett's sphericity test showed that the principal component analysis is applicable to all five datasets.

The eigenvalues and respective variances were calculated through the PCA. Table 1 shows an example for the $4^{\text {th }}$ trimester. Two different approaches were considered in the PCA. The first using the PC with eigenvalues higher than one (the Kaiser criterion) responsible for $54 \%$ to $72 \%$ of the total variance; the second using six PC responsible for all the variance. Considering the first approach, only the first two PC were selected in all datasets with exception for the $4^{\text {th }}$ trimester, where the first three PC were used.

Table 1: Eigenvalues and respective cumulative variances (\%) for each principal component for the $4^{\text {th }}$ trimester.

\begin{tabular}{|c|c|c|c|c|c|c|}
\hline & $\mathrm{PC}_{1}$ & $\mathrm{PC}_{2}$ & $\mathrm{PC}_{3}$ & $\mathrm{PC}_{4}$ & $\mathrm{PC}_{5}$ & $\mathrm{PC}_{6}$ \\
\hline Eigenvalue & 1.87 & 1.35 & 1.08 & 0.82 & 0.58 & 0.29 \\
\hline $\begin{array}{c}\text { Cumulative } \\
\text { variance (\%) }\end{array}$ & 31.2 & 53.7 & 71.8 & 85.5 & 95.1 & 100.0 \\
\hline
\end{tabular}

Table 2 shows, as an example, the rotated factor loadings using three PC and six PC, for the $4^{\text {th }}$ trimester. The bold marked loads indicate the variables that most influence the correspondent component. It was observed that using two PC (or three in the $4^{\text {th }}$ trimester) each component accounts for a higher number of variables than with six PC.

Table 2: $\quad$ Rotated factor loadings using two and six PC, for the $4^{\text {th }}$ trimester.

\begin{tabular}{|c|c|c|c|c|c|c|c|c|c|}
\hline \multirow{3}{*}{ Variables } & \multicolumn{9}{|c|}{ Rotated factor loadings } \\
\hline & \multicolumn{3}{|c|}{ Two PC } & \multicolumn{6}{|c|}{ Six PC } \\
\hline & $\mathrm{PC}_{1}$ & $\mathrm{PC}_{2}$ & $\mathrm{PC}_{3}$ & $\mathrm{PC}_{1}$ & $\mathrm{PC}_{2}$ & $\mathrm{PC}_{3}$ & $\mathrm{PC}_{4}$ & $\mathrm{PC}_{5}$ & $\mathrm{PC}_{6}$ \\
\hline $\mathrm{NO}_{2} / \mathrm{NO}$ & 0.076 & 0.033 & -0.952 & 0.074 & -0.054 & -0.983 & -0.134 & -0.078 & 0.033 \\
\hline $\mathrm{CO}$ & -0.676 & 0.202 & 0.338 & -0.048 & -0.013 & 0.148 & 0.956 & -0.054 & 0.241 \\
\hline $\mathrm{T}$ & 0.115 & 0.766 & 0.218 & 0.045 & 0.983 & 0.055 & -0.013 & -0.170 & -0.025 \\
\hline RH & 0.035 & $\overline{-} 28$ & 0.248 & -0.056 & -0.172 & 0.078 & -0.049 & 0.979 & 0.013 \\
\hline WV & 0.906 & 0.018 & 0.108 & 0.286 & 0.029 & 0.043 & -0.274 & -0.016 & -0.916 \\
\hline $\mathrm{O}_{3}$ & 0.702 & 0.238 & -0.049 & 0.962 & 0.047 & -0.081 & -0.047 & -0.059 & -0.246 \\
\hline
\end{tabular}

In the example shown, the variables that had most significant loads when using three $\mathrm{PC}$ were the concentration of $\mathrm{CO}$ and $\mathrm{O}_{3}$ and the $\mathrm{WV}$ for $\mathrm{PC}_{1}$, the $\mathrm{T}$ and $\mathrm{RH}$ for $\mathrm{PC}_{2}$ and the ratio $\mathrm{NO}_{2} / \mathrm{NO}$ for $\mathrm{PC}_{3}$. When using six $\mathrm{PC}$, each principal component had one variable with most significant load.

As mentioned before, the next day maximum ozone concentration was predicted through MLR and PCR models. The PC used in PCR were obtained multiplying standardized values of the original independent variables by the weights. The PCR was performed considering two (or three for the $4^{\text {th }}$ trimester) and six PC separately.

In both model approaches, a t-Test was used to statistically evaluate the regression coefficients. The following procedure was the development of new regressions using only the predictor variables with statistically valid coefficients. 
Considering three PCR, the statistically valid coefficients were the same using two or six PC, for all datasets, except for the $1^{\text {st }}$ trimester and for the annual datasets with one more valid parameter when using six PC. As an example, for the $4^{\text {th }}$ trimester, the variable used in the MLR was the wind velocity (WV) and in PCR, the valid $\mathrm{PC}$ were the $\mathrm{PC}_{1}$ and the $\mathrm{PC}_{3}$, which account for the $\mathrm{CO}$ and $\mathrm{O}_{3}$ concentrations and for the ratio $\mathrm{NO}_{2} / \mathrm{NO}$ and $\mathrm{WV}$, respectively.

In the development step, the performance indexes computed were very similar for both models with the exception of MBE, whose values were always lower with PCR (values between $-7.5 \times 10^{-7}$ and $-3.2 \times 10^{-6}$ ) than with MLR (values between -0.39 and -3.39 ).

For the models validation the periods used for each trimester and for the complete year were, respectively, the last 10 and 30 days.

The performance indexes calculated for the PCR model were better than those calculated for the MLR model. Table 3 presents the values of the performance indexes calculated during the validation step with both models, for the $4^{\text {th }}$ trimester and annual datasets.

Table 3: Performance indexes for both models, for the $4^{\text {th }}$ trimester and annual datasets, in the validation step.

\begin{tabular}{|c|c|c|c|c|}
\hline \multirow{2}{*}{$\begin{array}{c}\text { Performance } \\
\text { indexes }\end{array}$} & \multicolumn{2}{|c|}{$4^{\text {th }}$ trimester } & \multicolumn{2}{c|}{ Annual } \\
\cline { 2 - 5 } & MLR & PCR & MLR & PCR \\
\hline MBE & -37.47 & -3.30 & -2.32 & 0.23 \\
\hline MAE & 37.47 & 7.88 & 9.47 & 9.48 \\
\hline RMSE & 39.51 & 9.90 & 11.72 & 11.43 \\
\hline IA & 0.140 & 0.89 & 0.84 & 0.82 \\
\hline
\end{tabular}

As an example, figs. $1 \mathrm{a}$ and $1 \mathrm{~b}$ show the predictions with both models and the measured data corresponding to the $4^{\text {th }}$ trimester and the annual validation periods. As can be seen the PCR model performance was superior throughout the validation period. It was also verified that the PCR model improved significantly the prediction of the ozone concentrations, showing to be a useful tool to provide the protection of the public health, through the early warnings of the population.

\section{Conclusions}

MLR and PCR were applied to predict the next day maximum of $\mathrm{O}_{3}$ concentration. The variables initially used in the prediction models were the maxima hourly values for $\mathrm{O}_{3}$, ratio of $\mathrm{NO}_{2} / \mathrm{NO}, \mathrm{T}, \mathrm{WV}$ and the minima hourly values for $\mathrm{CO}$ and $\mathrm{RH}$. Several variables were removed during the procedure to obtain significant statistical models.

In the development step, the performance indexes computed were very similar for both models with the exception of MBE, whose values were always lower with PCR than with MLR. In the validation step, the performance indexes calculated for the PCR model were better than those calculated for the MLR model. 
Concluding, multiple linear regression based on principal components was more robust because it eliminated collinearity problems and reduced the number of variables presented in multiple regression models. It was also verified that PCR model improved significantly the prediction of the ozone concentrations, showing to be a useful tool to provide the protection of the public health, through the early warnings of the population.

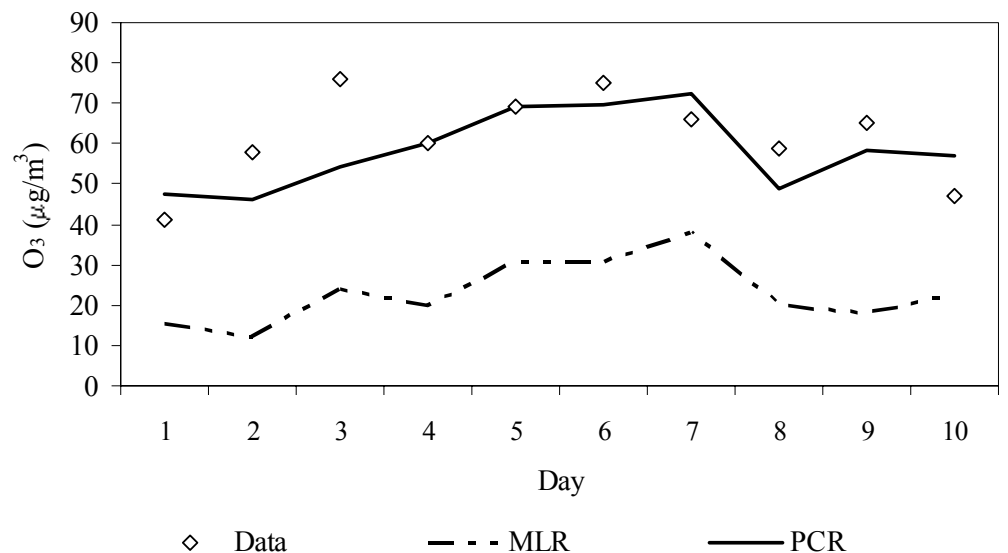

(a)

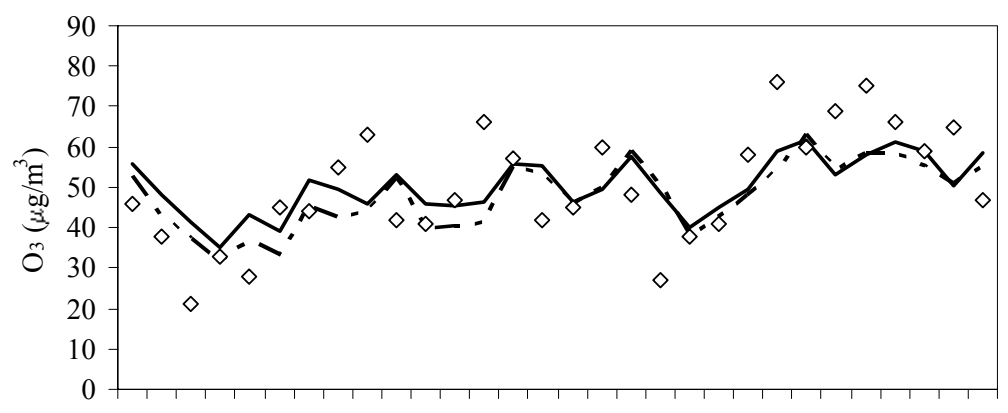

123456789101112131415161718192021222324252627282930

Day

$$
\diamond \text { Data - - MLR PCR }
$$

Figure 1: Prediction of $\mathrm{O}_{3}$ concentrations for: a) $4^{\text {th }}$ trimester dataset, b) annual dataset.

\section{References}

[1] White, M. C., Etzel, R.A., Wilcox, W. D. \& Lloyd C., Exacerbation of childhood asthma and ozone pollution in Atlanta. Environmental Research, 35, pp. 56-68, 1994. 
[2] WHO, Air Quality Guidelines, World Health Organization Regional Office, Copenhagen, 2000.

[3] Seinfeld, J. H. \& Pandis, S. N., Atmospheric Chemistry and Physics from Air Pollution to Climate Changes, John Wiley Sons, USA, 1998.

[4] Alvim-Ferraz, M. C. M., Sousa, S. I. V., Pereira, M. C. \& Martins, F. G., Contribution of anthropogenic pollutants to the increase of tropospheric ozone levels in Oporto Metropolitan Area, Portugal since the $19^{\text {th }}$ century. Environmental Pollution, in press, 2005.

[5] Gonçalves, F. L. T., Carvalho, L. M. V., Conde, F. C., Latorre, P. H. N. \& Braga, A. L. F., The effects of air pollution and meteorological parameters on respiratory morbidity during the summer in São Paulo City. Environment International, 31, pp. 343-349, 2005.

[6] Abdul-Wahab, S. A., Bakheit, C. S. \& Al-Alawi, S. M., Principal component and multiple regression analysis in modelling of ground-level ozone and factors affecting its concentrations. Environmental Modelling \& Software, 20, pp. 1263-1271, 2005.

[7] Lengyel, A., Héberger, K, Paksy, L., Bánhidi, O. \& Rajkó, R., Prediction of ozone concentration in ambient air using multivariate methods. Chemosphere, 57, pp. 889-896, 2004.

[8] Pereira, M. C., Alvim-Ferraz, M. C. M. \& Santos, R. C., Relevant aspects of air quality in Oporto Portugal): $\mathrm{PM}_{10}$ and $\mathrm{O}_{3}$. Environmental Monitoring and Assessment, 101, pp. 203-221, 2005.

[9] Heo, J-S. \& Kim, D-S. A new method of ozone forecasting using fuzzy expert and neural network systems. Science of the Total Environment, 325, pp. 221-237, 2004.

[10] Thompson, M. L., Reynolds, J., Cox, L. H., Guttorp, P. \& Sampson P. D., A review of statistical methods for the meteorological adjustment of tropospheric ozone. Atmospheric Environment, 35, pp. 617-630, 2001.

[11] Çamdevýren, H., Demýr, N., Kanik, A. \& Keskýn, S., Use of principal component scores in multiple linear regression models for prediction of Chlorophyll-a in reservoirs. Ecological Modelling, 181, pp. 581-589, 2005.

[12] Slini, T., Kaprara, A., Karatzas, K. \& Moussiopoulos N., PM 10 forecasting for Thessaloniki, Greece. Environmental Modelling \& Software, in press.

[13] Peres-Neto, P. R., Jackson, D., A. \& Somers, K., M., How many principal components? Stopping rules for determining the number of non-trivial axes revisited. Computational Statistics \& Data Analysis, in press.

[14] Chaloulakou, A., Saisana, M. \& Spyrellis, N., Comparative assessment of neural networks and regression models for forecasting summertime ozone in Athens. Science of the Total Environment, 313, pp. 1-13, 2003.

[15] Gardner M., W. \& Dorling, S. R., Statistical surface ozone models: an improved methodology to account for non-linear behaviour. Atmospheric Environment, 34, pp. 21-34, 2000. 